\title{
The ANP/cGMP/cGMP-dependent protein kinase pathway counteracts Angiotensin II-stimulated calcium mobilization in cardiac myocytes
}

\author{
Michael Klaiber*1, Katharina Völker1 ${ }^{1}$, Birgit Gaßner ${ }^{1}$, Andrea Gerling², \\ Susanne Feil2, Robert Feil ${ }^{2}$ and Michaela Kuhn ${ }^{1}$
} \author{
Germany \\ Email: Michael Klaiber* - michael.klaiber@uni-wuerzburg.de \\ * Corresponding author \\ from 4th International Conference of cGMP Generators, Effectors and Therapeutic Implications \\ Regensburg, Germany. 19-21 June 2009 \\ Published: II August 2009 \\ BMC Pharmacology 2009, 9(Suppl I):P34 doi:I0.1 I86/I47|-22I0-9-SI-P34
}

Address: ${ }^{1}$ Institute of Physiology, University of Würzburg, Germany and ${ }^{2}$ Interfakultäres Institut für Biochemie (IFIB), University of Tübingen,

This abstract is available from: http://www.biomedcentral.com/I47I-2210/9/SI/P34

(C) 2009 Klaiber et al; licensee BioMed Central Ltd.

\section{Background}

The cardiac hormone atrial natriuretic peptide (ANP) exerts local, Guanylyl Cyclase-A (GC-A) - mediated myocardial effects to antagonize the $\mathrm{Ca}^{2+}{ }_{\mathrm{i}}$-dependent hypertrophic growth response to Angiotensin II (Ang II). The present study aimed to characterize the specific molecular mechanisms mediating the reciprocal interactions between the ANP/GC-A and the Ang II/AT1 systems in the heart.

\section{Results}

$\mathrm{Ca}^{2+}{ }_{\mathrm{i}}$-transients and cell shortening were monitored in Indo-1 loaded isolated, electrically paced adult murine cardiomyocytes. Ang II (1-100 nM) acutely enhanced the amplitude of $\mathrm{Ca}^{2+}{ }_{\mathrm{i}}$-transients, accelerated $\mathrm{Ca}^{2+}{ }_{\mathrm{i}}$-decay and stimulated cell shortening. These effects were completely prevented by ANP (100 $\mathrm{nM})$. In contrast, the myocyte calcium responses to $\beta$-adrenergic stimulation $(10 \mathrm{nM}$ isoprenaline) were not affected by ANP. To study the role of cGMP-dependent protein kinase I (PKG I), we evaluated the ANP effects on calcium regulation in myocytes from transgenic mice with cardiac deletion of PKG I. The inhibitory effects of ANP on Ang II signaling were totally abolished in PKG I-deficient myocytes. Rp-8-pCPT-cGMPs, a membrane-permeable PKG inhibitor, mimicked the effects of genetic PKG I deletion. One downstream target of PKG I in the heart is regulator of G-protein signaling
(RGS)-2, which attenuates Ang II - Gaq protein signaling. In RGS2 - deficient myocytes Ang II - induced $\mathrm{Ca}^{2+}{ }^{-}$ mobilization was enhanced. Moreover, the inhibitory effect of ANP was totally abolished.

\section{Conclusion}

Taken together, our data indicate that PKG I is a downstream target activated by the ANP/GC-A/cGMP-signaling pathway in cardiac myocytes. cGMP/PKG I-stimulated phosphorylation of RGS2 and subsequent inhibition of AT1/Gq-signaling appear to mediate the counterregulation of the cardiac effects of Ang II by ANP.

\section{Acknowledgements}

Supported by Sonderforschungbereich SFB 487 